\title{
DỨBin
}

Technological University Dublin ARROW@TU Dublin

\section{Kíla: Éacht!!! Ag Féile Gormacha Tuaithe an Chlocháin '91}

Máirtín Mac Con lomaire .

Technological University Dublin, mairtin.macconiomaire@tudublin.ie

Follow this and additional works at: https://arrow.tudublin.ie/tfschafart

Part of the Music Commons

\section{Recommended Citation}

Mac Con Iomaire, M. (1991). Kíla: Éacht!!! Ag Féile Gormacha Tuaithe an Chlocháin '91. Comhar. Imleabhar 50, Uimhir 9, Ith. 21, DOI: 10.21427/d7mx9h

This Article is brought to you for free and open access by the School of Culinary Arts and Food Technology at ARROW@TU Dublin. It has been accepted for inclusion in Articles by an authorized administrator of ARROW@TU Dublin. For more information, please contact arrow.admin@tudublin.ie, aisling.coyne@tudublin.ie, gerard.connolly@tudublin.ie.

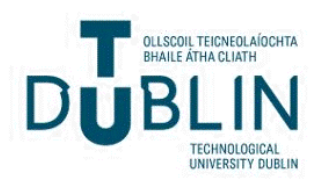




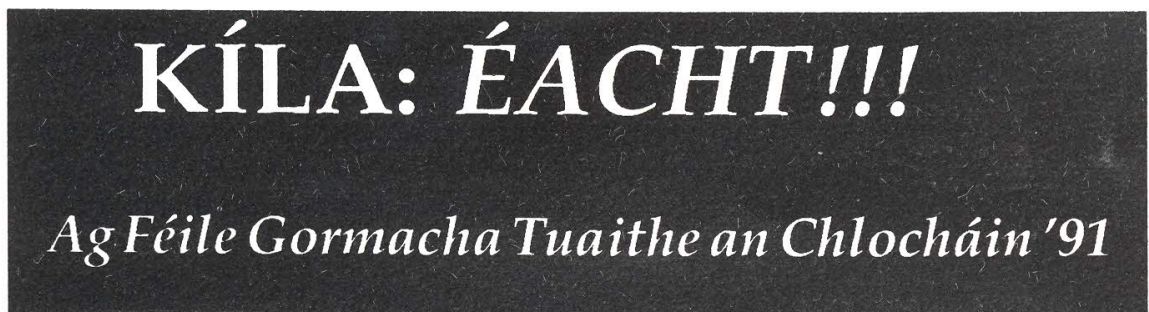

\section{3 - 15 Meán Fómhair}

Dé hAoine. Shroich mé an Clochán tráthnóna Dé hAoine thart ar a sé a chlog agus é ag brádán, mar is dual d'aimsir Chonamara. Rinneamar ár mbealach go mall trí na sluaite go dtí an pháirc imeartha, áit a raibh mórán ag campáil. Suas leis na pubaill agus isteach sa mbaile linn. Bhí triú féile Country Blues an Chlocháin ar tí tosú!

Casadh cairde orainn taobh amuigh de theach óil "Humanity Dicks", áit a raibh an banna ceoil Kíla (iarscoláirí as Coláiste Eoin) ag seinm ceoil an oíche sin. Bhí scéalta á n-aithris, pleananna á ndéanamh agus pórtar á ól! Bhí Kíla le tosú ar a deich, rud a d'fhág uair nó dhó againn le hatmaisféar na háite a shú isteach. Bhí snagcheol (Jazz) den scoth ar siúl in óstán an "Abbey Glen" leis an bhfear cáiliúl Georgie Fame agus Louis Stewart agus ceoltóirí eile. Orthu sin bhí Keith Donald, iar-cheoltóir leis na "Moving Hearts".

Deich a chlog agus bhí na sluaite ag brú a mbealach isteach sa "Best Cellar" (thíos staighre i "Humanity Dicks"), áit a raibh Kíla ag seinm. Bhí an áit dubh le daoine agus níorbh fhada go raibh draíocht an cheoil ag dul i bhfeidhm ar an slua agus iad ag luascadh agus ag damhsa. I rith na hoíche, rinne Kíla éacht ar an stáitse - bhí aon duine dhéag ag seinm uirlisí éagsúla le chéile uair amháin. Ceol mór cumhachtach ba ea é seo. Seinneadh 'Tiggys Jigs' agus 'Ard Aoibhinn' agus bhí sé soiléir ar shíorghluaiseacht an lucht féachana go raibh cách ag baint sás as an gceol. Ach ba é "Ri na Síog" a rug leis an slua corp fíochmhar suaite amháin ba ea an lucht féachana ina iomláine i rith an phíosa ceoil seo. Tháinig Rónán Ó Snodaigh (cnaguirlisí) chun tosaigh agus chas ceol Reggae Gaeilge a chum sé féin. Shílfeá ar a fhuinneamh agus ar a ghruaig fhada chatach dhubh nach i nDumhach Trá ach i Jamaica a rugadh é! Gan oiread agus sos amháin in imeacht dhá uair $\mathrm{a}^{\prime}$ chloig go leith ceoil, bhí an grúpa chomh spionta sin nach bhféadfaidís leanacht orthu cé go raibh an slua ag impí agus ag éileamh tuilleadh ceoil. Fhad is a bhí Kila ag seinm sa 'Best Cellar', bhí Diz Honey Bear Watson, Tony Uter, Henry Mc Cullough And His Band, The Red Peters Blues Band, Stepaside, The Higgler Jug Band agus The Rye River Boys ag seinnt in áiteanna éagsúla ar fud an Chlocháin. Sár-oíche ceoil ba ea é, agus lean ceol eile ar aghaidh go deireanach san oíche timpeall ar thinte cnámh sa láthair campála áit ar casadh neart amhrán!

Dé Sathairn. Thosaigh an chéad cheol ar a leathuair tar éis a ceathair ar stáitse a tógadh go speisialta i lár an bhaile. Bhí ceol ón Mississippi Delta ag na Rye River Boys agus ceol tíre ag na Long Riders. Bhí an aimsir go hálainn agus bhí an slua ag cur fírinne sa seanfhocal, gurb é leigheas na póite ól arís! Bhí briseadh ann ina dhiaidh sin go dtí a deich a chlog rud a thug seans don slua dul ag siúl, ag snámh nó ag srannadh!

I dteach óil "Griffin's" (The Cavern) a chuala mé Diz Honey Bear Watson and His Irish Rock' $n$ Roll chomh maith le neart ceoil boogie woogie ó New Orleans. Bhíodar ar fheabhas. As sin go dtí "Guy's Rockin' Lounge" áit a raibh The Red Peters Blues Band ag déanamh ceoil. Scoth ceoltóirí is ea iadsan agus bhí ceol chomh Doormen agus iad ag seinm
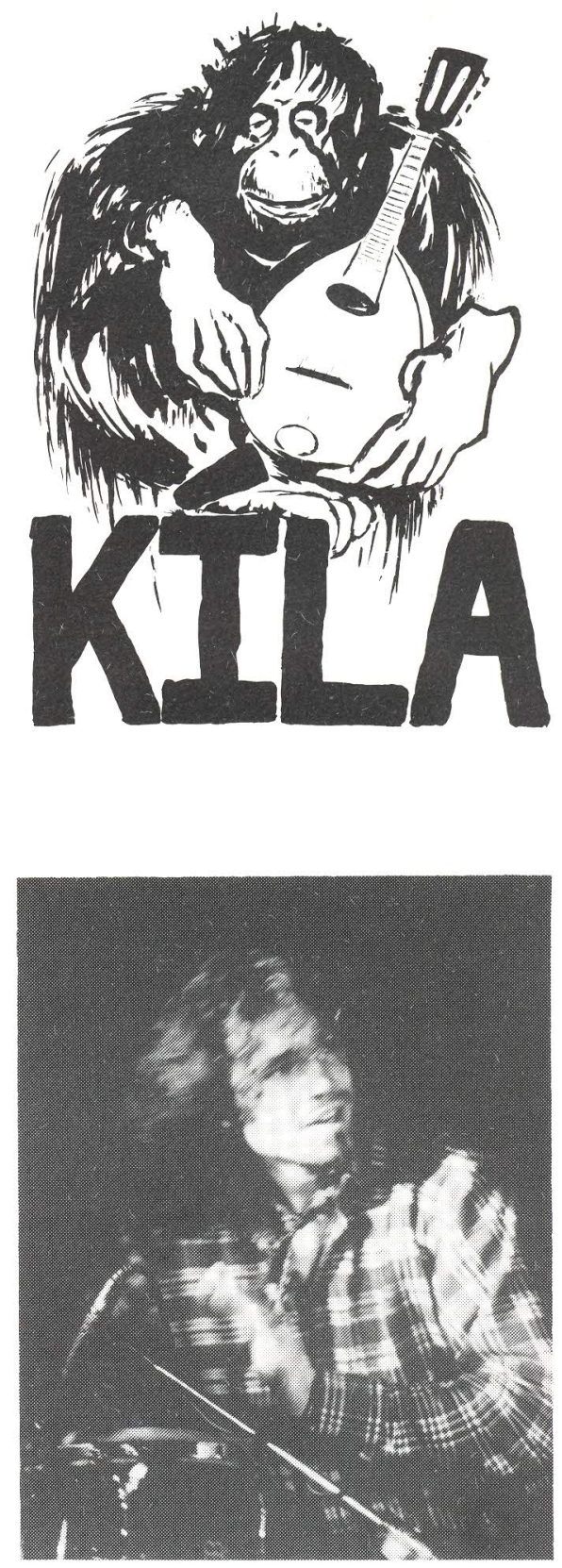

Rónán Ó Snodaigh

binn á bhaint as a ghiotár ag duine den ghrúpa go sílfeá gurb é James Galway gan a fheadóg óir a bhí ag seinm. Thóg gach ball den bhanna ceoil a sheal féin ag casadh na "ngormacha" (seachas an drumadóir) agus ba dheacair dom mé féin a stracadh as an áit ar 12.30 le dul ag éisteacht leis an ngrúpa óg Bleácliathach, The Frames, $i$ halla an bhaile.

Agus ní raibh sa mhéid sin ar fad ach "tús an phota"...

Máirtín Mac Con Iomaire 